Please refer to the definitive version of this article when citing:

Kimber, S., Yang, J. \& Cohen, S. (2019). Performing love, prosperity and Chinese hipsterism: Young independent travellers in Pai, Thailand. Tourist Studies, DOI: 10.1177/1468797619833367

\title{
Performing love, prosperity and Chinese hipsterism: young independent travellers in Pai, Thailand
}

\begin{abstract}
Young independent Chinese travellers are increasingly visiting Pai, a small town in northern Thailand, in part influenced by the popularity of the 2009 Thai movie 'Pai in Love'. Using a performance perspective, combined with theory on affordances, which have not not yet been applied in the growing body of research on Chinese tourists, this paper examines the wide variety of performances in Pai by young independent Chinese travellers, many of which revolve around tourist photography. Drawing upon participant observation and in-depth interviews with Chinese travellers in Pai, the findings reveal that many young Chinese independent traveller performances in Pai revolve around the creation of online self-identities of prosperity and globalisation, love and alternative social identities such as Chinese hipsterism or Xiao Qing Xin. Central to many of these hybrid performances is the digital camera, which affords new, more playful, embodied ways of encountering and interacting with tourist attractions, whilst simultaneously offering a means of recording and refining performances which are then distributed via the 'statusphere'. The paper's use of a performance lens provides new insights into Chinese tourism consumption, and highlights the importance of physical, material and social affordances in performing tourism.
\end{abstract}

Keywords: Performance turn, Affordances, Young Chinese independent travellers, Social capital, Digital photography, Thailand

\section{Introduction}

The development of tourism in China is a relatively recent and rapidly evolving phenomenon, and like Chinese society, is undergoing sweeping changes (Ong and du Cros, 2012). This paper focusses on one expanding and diversifying group that of young Chinese independent or selforganised travellers, of which relatively little is known about, particularly their patterns of tourism production and consumption. And whilst research on Chinese tourists has rapidly grown in the last decade, it has yet to really focus on Chinese tourist performances such as photography (beyond an initial study by Li et al, 2017 on their photographic gaze), or to conceptualise such actions as performances. Drawing on the 'performance turn', which developed in tourism studies from the 1990s onwards (see Edensor, 1998; Crouch, 2000, Baerenholdt et al, 2004), this paper support's despite Haldrup and Larsen's (2009, p2) contention that tourist consumption can be fruitfully approached and considered through the 
'lens of performance'. Taking performance as a metaphor for tourist practice, this paper examines the wide variety of performances, many of which revolve around tourist photography in Pai, a small town in northern Thailand, by young independent Chinese travellers. The paper thus aims to use a performance lens to provide new understandings of Chinese tourism consumption.

The performance turn (Edensor, 2001; Baerenholdt et al, 2004; Crouch, 2004) seeks to conceptualise tourism as a performance by shifting focus towards ontologies of acting and doing (Franklin and Crang, 2001), and by acknowledging the corporeality of tourist bodies and their creative potentials, as well as the significance of technologies and the material affordances of places (Haldrup and Larsen, 2009). It is argued that tourists experience places in multisensuous ways (Haldrup and Larsen, 2009; Jensen et al, 2015), through corporeal proximity as well as virtually and through imaginations. Metaphorically, in addition to just looking at 'tourism stages', tourists step into them and enact in them corporeally. For Haldrup and Larsen (2009), photographing is an emblematic and all-consuming tourism performance, not just because of the social value of photographs, but also because the act of photography can also be seen as an end in itself, a playful source of pleasure and a holiday act. By considering tourist performances such as photography and other embodied performances, the performance perspective highlights that consumption and production are hybrid and mutual processes that occur alongside each other, dissolving distinctions between producer and consumer (Bærenholdt et al 2004; Johannesson, 2005; Ek et al, 2008). Using dramaturgical metaphors to describe how tourism takes place through concrete encounters and enactment, this study adopts a 'practice -inspired performance perspective', which Larsen (2005) and Ek et al (2008) argue can provide insights and understanding into the nature of tourism production and consumption that are not possible using conventional representational approaches.

After tourism studies' initial preoccupation with backpacker, budget and youth tourism practiced by citizens from affluent 'developed' countries, attention is beginning to turn to travellers from developing economies and fast-expanding urban spaces in Asia (Ong \& du Cros, 2012). Despite a growing body of literature on young Chinese travellers and backpackers mostly in mainland China (Lim, 2009; Chen and Weiler, 2014; Luo et al 2015), there are still few studies on Chinese independent travel, especially on outbound travel (Prayag et al, 2014). 
Although Thailand as a whole is popular with Chinese outbound travellers, Pai, a small town in northern Thailand near Chiang Mai, once visited mostly by Western backpackers and Thai domestic tourists, has suddenly become a popular destination amongst young Chinese independent travellers due in part to the popularity of the 2009 Thai movie 'Pai in love'. Although never officially released in Chinese cinema due to state restrictions that limit the number of foreign film cinematic releases to just 34 a year (Papish,2017), 'Pai in Love' found its way onto online video streaming Chinese websites such as Youku and IQiyi. It is estimated that IQiyi alone has over 500 million active, and mostly young Chinese users (Armstrong and Wang, 2018), where it gained something akin to cult status amongst young Chinese viewers, and there are even websites that can help fans to learn key phrases from the movie (e.g. https://th.hujiang.com/new/p540002/). The film is intimately connected to Pai in the minds of many young Chinese and is prominently mentioned in nearly every Chinese travel blog on Pai.

As a destination, Pai is fairly unique in Thailand in that it has not yet attracted the attention of Chinese tour groups. This paper draws on the results of an ethnographic study in Pai in 2016 carried out by the lead author, which was part of a wider study on the gazes and performances of young Chinese travelers, and utilized extensive participant observation and in-depth interviews. The paper seeks to reveal the unique and culturally specific nature of performances carried out by young Chinese independent travellers in Pai, and also the contribution a performance approach can offer in understanding the nature of young Chinese touristic consumption and production. The paper will first consider the performance aspects of tourist photography in addition to theory of performances and affordances in tourism, before turning its attention to the findings of this research.

\section{Tourist Photography}

Ever increasing numbers of photographs are being uploaded onto social media daily. Just within Western social media alone, it was estimated that in 2013 , over 500 million images a day were posted online (Meeker, 2013) and in 2018, it is estimated that on Instagram alone, 100 million images and videos are shared online each day (Omnicore, 2018). Such patterns of posting social media content are also seen in China, albeit on its own platforms. The largest Chinese social media platform, Wechat, has 1 billion users, and after Snapchat, is the second largest social media platform in the world, with an estimated 68 million photographs and 
videos posted daily on it (Dogtiev, 2018; Scott, 2018). The rise of sharing photographs online is inextricably linked to digital photography, and Germann Molz and Paris (2015) argue that online social networking sites have combined and assembled together with technological devices such as digital cameras and smartphones to afford people new forms of sociability. Li et al (2017) also similarly highlight that this digital revolution in technology is challenging not only the traditional sociology of photography in general (Bourdieu, 1996; Harrison, 2004) but also the role and significance of photography in the tourist experience in particular (Larsen and Sandbye, 2014; Lo and McKercher, 2015).

Larsen (2008) also asserts that the digital camera has completely revolutionised the way tourist photography is carried out. Barthes (2000) called analogue photography 'that has been' because photographs always depicted past events taking place elsewhere, and holiday snap-shots tended to be both static and limited, in part due to the cost of processing and developing images. For Urry (1990), analogue photography was a ritualised component of the tourist gaze, an ocular centric consumption of foreign places. However, the digital camera has revolutionised tourist photography, changing it from a passive to an embodied and pro-active activity (Edensor, 2000), where photographs are 'unlimited' and the camera screen has turned photography into a collaborative event (Larsen, 2005). Digital cameras and smartphones have afforded new, more playful, embodied ways of encountering and interacting with tourist attractions. Subjects and photographer can now co-produce images by evaluating images in real time, deciding which images should be kept, or indeed insisting if an image should be retaken, perhaps many times. And increasingly, tourist photography is becoming central to the whole act of tourism (Scarles, 2009).

In terms of Chinese tourist photography, Yeh (2009) argues that for many Chinese, photography is less about capturing the landscape or the 'picturesque', but rather more about framing images for the consideration of others such as family members. Increasingly, and not just by Chinese tourists, photography and social media is becoming ever more bound up with 'self-presentation and strategic impression management' (Goffman, 1959, p. 10), and is very much a theatrical act (Larsen, 2008) and a performance that 'lights up the tourism experience' (Scarles, 2009, p484). Urry and Larsen (2011) suggest that many tourists have present, future and imagined audiences in mind when they pose for a camera, and at the core of this is presenting an idealised image or socially desirable image of one-self to others. This article 
argues, that given that photo-taking and sharing has become ubiquitous and omnipresent in Chinese society (Seta and Proksell, 2015; Zhang,2017), and 'selfies' have become an everyday performative and social practice that has also become ingrained into contemporary Chinese touristic practices. However, at present, little research has been carried out on identifying the cultural uniqueness of Chinese tourist photography apart from a study by Li et al (2017) on their photographic gaze which is heavily influenced by state narratives of modernity (see Oakes, 1998) and by digital technology.

\section{Performances in Tourism}

A body of literature exists that proposes that tourist photography is a performance of tourism (e.g. Edensor, 2000; Larsen, 2005; Haldrup and Larsen, 2009) and self (Cederholm, 2004; Urry and Larsen, 2011) (Lo and McKercher, 2015). Initially used as a means of destabilizing the visual hegemony that writers such as Veijola and Jokinen (1994), Wearing and Wearing (1996) and Larsen (2005) argued existed in tourism studies, the performance turn in tourism studies sees performance as an analytical lens that shifts the focus of research away from one dimensional narratives such as the visual gaze (Johannesson, 2005). Tourists experience places in multisensuous ways (Haldrup and Larsen, 2009; Jensen et al, 2015), which involve multiple bodily sensations: touching, tasting, smelling and hearing. Tourists encounter tourism places and spaces through corporeal proximity as well as virtually and through imaginations. Metaphorically, in addition to just looking at 'tourism stages', tourists step into them and enact in them corporeally. The performance turn (Edensor, 2001; Baerenholdt et al, 2004; Crouch, 2004) seeks to conceptualise tourism as a performance by shifting focus towards ontologies of acting and doing (Franklin and Crang, 2001), and by acknowledging the corporeality of tourist bodies and their creative potentials, as well as the significance of technologies and the material affordances of places (Haldrup and Larsen, 2009). By considering how tourist places are performed by tourists, a performance perspective highlights that consumption and production are hybrid and mutual processes that occur alongside each other, dissolving distinctions between producer and consumer (Bærenholdt et al 2004; Johannesson, 2005; Ek et al, 2008). 
Within social science and also tourism studies, many performance analyses draw heavily on the work of Erving Goffman (1959) and his widely acclaimed book 'The Presentation of Self in Everyday Life' (Velten, 2012). For Goffman, the self is a performed character, a public performer with a carefully managed stage impression (Larsen, 2005). Everyday life or 'being in the world' is considered as being fundamentally performative, acted out on a stage for an audience. People, or in this case, tourists, are everyday actors that move between different stages or spaces that require and allow for specific performances. Central to these public performances is the notion that "a correctly staged and performed scene leads the audience to impute a self of a performed character, but this imputation-the self-is a product of the scene that comes of it" (Goffman, 1959, p252). Also, key to the work of Goffman is that of impression management or self-presentation, which is the effort and strategies employed to manage a beneficial image of self in the presence if others. In tourism, its is argued that most performances are co-performed collectively, socially negotiated not only between actors but also with a present or imagined audience in mind. Part of the appeal of social media and social network sites is their ability to create and manage impressions, to experiment and construct one's identity (Whitty, 2007). However, although Sung et al (2016) argue that one of the main reasons for social networking and posting photographs is that of self-presentation, increasingly, selfie posting is also seen as a source of entertainment and fun (see also Yang and Li, 2014).

Whilst the work of Goffman (1959) has been highly influential, it is by no means the only perspective to have influenced the 'performance turn' in tourism studies. Butler (1993) puts a different approach to performance; that of performativity, emerging out of her writing on the construction of gender and sex (Larsen, 2005). Building on the work of Austin (1955) and his idea of performative speech acts, Butler argues that identities do not emerge from any singular enactment of an expression such as suggested by Goffman, be it linguistic, musical, or in this case, in the field of tourism. Neither do identities pre-exist their performance. Instead, the performative are actions and utterances, that through repetition and constant recycling, become so routinized as to appear natural. A performative approach argues that in many cases tourism is shaped by ritualised practice, daily flows and routines and by Foucauldian notions of unequal power-relations (Gregson \& Rose, 2000). 
In recent years, human geography and in particular non-representational theory have picked up and developed many of the tenets of performance and also that of performativity. For instance, Thrift $(1997,2000)$ considered the pre-presentational and pre-choreographed aspects of performances, disagreeing with Goffman's notion of the 'calculating actor' yet finding Butler's notion of 'performance' too scripted and too constraining a way of thinking about the conditions and conditioning of reality. Likewise, Crouch's (2003, p. 1946) practicebased (and more materiality based) notion of performativity deviates from more rigid notions of performativity in that it acknowledges the "unexpected, the different, the risky" . However, of most theoretical relevance to the present paper is the notion of a 'practice-based performance approach' (Larsen, 2005; Ek et al, 2008). Bridging the ground between performance and performativity and taking Thrift's $(1997 ; 2000)$ ideas one step further, this approach acknowledges that performances can be at times choreographed as all stages have pre-existing discursive, practical, embodied norms and guidance. In the case of Pai, the culturally specific performances of young Chinese travellers highlight the significant role guidebooks (such as Mafengwo), online blogs and existing place myths (movies, word-ofmouth and social media) play in shaping performances. In addition, Larsen (2005) takes greater account of the influence and hybridity, social and material affordances play in enabling performances. Over reliance on Goffmanian (1959) theatrical metaphors risks creating the idea that space is an empty stage, a relatively fixed container for social action, waiting to be filled by performers (Haldrup and Larsen, 2009). The use of the concept of affordances, as discussed below, counteracts this tendency by reinstating the potentialities of space and place.

\section{The role of Affordances}

Of key significance to the understanding of performances in tourist destinations is how material culture and objects affect the production and consumption of tourism. Edensor (2006) has argued that tourism studies had failed to consider how embodied subjects physically interact with space and objects, and in a similar vein, Cohen and Cohen (2017) argue that tourism studies still needs to relinquish its human-centric focus as the study of materialities in tourism can allow for a more complex understanding of how tourism is produced. 
Central to this is Gibson's (1979 p.127) theory of affordance, which is deceptively simple: "The affordances of the environment are what it offers the animal, what it provides or furnishes, either for good or ill" (Chemero, 2003). An affordance is a resource that the environment offers any animal that has the capabilities to perceive and use it. At a very basic level, affordances are about how environments can provide opportunities for particular kinds of behaviour such as the ability to run or to hunt more effectively. Although such ideas have their roots in ecological psychology, Gibson's (1979) theory of affordance has become of wider interest to social sciences. In recent years there has been a nascent consideration of affordances in tourism studies, especially the role material objects offer in shaping tourism. Within tourism studies, the use of affordances has been used to reinstate the potentialities of space and place, as 'the surfaces, textures, temperatures, smells, sounds, contours, gradients and pathways of places encourage humans to follow particular courses of actions' (Edensor, 2006, p3). Studies by Baerenholdt et al. (2004), Veijola and Valtonen (2007) and Rantala (2010) have considered how the physical attributes of space enable performances, and as such, remain close to Gibson's (1979) original ecological vision of affordance.

Of most interest to the present study is Germann Molz and Paris' (2015) attempt to move beyond the physical possibilities for embodied action to consider the social affordances of technology in backpacking. They build on Larsen's (2008) analysis of digital photography and highlight how the digital camera affords many hybrid tourist performances and has changed the nature of how many tourist places are encountered. Also, of key relevance for Germann Molz and Paris (2015) is the social affordances gained through the editing and distribution via social media on the so-called 'statusphere' (Solis, 2009) of images which affords ever greater opportunities for sharing performances between (travellers) and their distant friends and families. Whilst the smartphone affords travellers a virtual mooring in the statusphere, its real-time access to the internet also plays a significant role in furthering a hermeneutic circle of representation and tourism consumption.

The key contribution of affordances is that the perspective highlights how tourism objects and technologies are crucial in shaping embodied actions and tourism performances, as they "enhance the physicality of the body and enable it to do things and sense realities that would otherwise be beyond its capabilities" (Haldrup and Larsen, 2009, p7). By placing a greater emphasis on trying to understand how social reality is constructed and how performances are 
produced, consideration of affordances can further tourism studies' understanding of performances and move beyond Goffman (Larsen, 2005; Ek et al, 2008). Affordances should not necessarily be studied in isolation, but as part and parcel of a wider consideration of the performances of tourism.

\section{Research Site}

Pai itself is a backpacker enclave in the north-western corner of Thailand. Popular since the 1990s, it grew rapidly in the mid 2000's to become according to Cohen (2006), the largest backpacker enclave in northern Thailand, and a northern counterpart to Phangan Island in the south and to the Khao San Road in Bangkok. Until very recently, Pai was predominantly frequented by Western backpackers.

Thai domestic tourism noticed Pai in the mid 2000's (Cohen, 2006) in part due to its cool winter climate: Thai media has dubbed the area 'the Switzerland of Thailand'. However, the 2012 Chinese comedy movie 'Lost in Thailand' changed this and put northern Thailand on the tourist map, and in 2013, Thailand's convention and exhibition bureau marketing communications director, Parichat Svetasreni, went so far as to thank "the Chinese movie Lost in Thailand for bringing a lot of Chinese travellers to Thailand" (FT, May $3^{\text {rd }}, 2013$ ). This surge in interest in northern Thailand then led to the rediscovery of the 2009 Thai film 'Pai in Love'. Despite the Thai romantic movie's low budget, it helped to create an image of Pai as a place of love. "Pai symbolizes LOVE" according to 'Kampungboy Citygal's' blog (Kampungboycitygal.com, 2015) and many other Asian blogs, and a quick search on Google and Baidu (Chinese equivalent of Google; 14/5/2018 search) will produce a huge number of images which associate Pai with romance and love. Largely as a result of growing Chinese interest in Thai movies and TV series (Thaitrakulpanich, 2016) and online media interest in Pai and 'Pai in Love', large numbers of young Chinese travellers started to visit Pai as an add-on destination to already popular Chiang Mai. In 2016, the lead author estimated that during the summer fieldwork period, Chinese tourists (predominately young independent travellers) made up about $60 \%$ of the visitors to Pai, with the remaining $40 \%$ being mostly Western, but this changes in the cool winter season (February) when Thai domestic tourists visit, with the visitor demographic being roughly $20 \%$ Thai, $50 \%$ Chinese and 30\% Western. English language travel blogs are now starting to comment on the "crushes and droves of Chinese tourists" 
(Hirsch, 2016, np), and Chinese internet and travel sites (such as Mafengwo) are awash with articles and comments about Pai. In fact, virtually every interviewed Chinese respondent in this study had heard anecdotally about Pai from friends and encountered articles extoling the virtues of Pai online. As a result, Pai is gradually evolving into a mass tourism resort, although as of 2016, it still had much of the trappings and feel of a backpacker destination.

\section{Research Methodology}

This paper is based upon four months of ethnographic research conducted by the lead author which was part of a wider study on the gazes and performances of young Chinese travellers in the backpacker enclave of Pai in northern Thailand in the summer of 2016. After an initial immersion period of one-month, mixed method ethnographic research utilizing extensive participant observation with in-depth interviews was carried out. Twenty Chinese traveller group interviews and two individual traveller interviews (Figure one) were carried out at a number of popular attractions in Pai, with the main selection criteria being that they were independent travellers, as opposed to having organised their trip through a package tour. A cross-section of ages, gender and group types (couples and friendship groups) were interviewed. Demographically, the interview respondents broadly reflected the type of Chinese independent travellers that visit Pai in that they were on the whole young, affluent and highly educated (many on graduation trips) and from major cities in mainland China, mirroring studies by Chen et al (2014) and Prayag et al (2015). Of interest was the lack of single male travellers or friends, but this is likely to be in part a reflection of Pai's reputation as a 'place of love' and therefore, most respondents were young couples or female friends travelling together. 
Figure 1 - Summary profile of respondents

\begin{tabular}{|c|c|c|c|c|c|}
\hline $\begin{array}{l}\text { Intervie } \\
\text { w }\end{array}$ & $\begin{array}{l}\text { Respondent's English } \\
\text { names }\end{array}$ & $\begin{array}{l}\text { Respondent's } \\
\text { relationship }\end{array}$ & $\begin{array}{l}\text { Age } \\
\text { Group }\end{array}$ & Educational attainment & $\begin{array}{l}\text { Location in } \\
\text { China }\end{array}$ \\
\hline 1 & Nathan and Nancy & Couple & $25-30$ & Graduate - now working & Guangzhou \\
\hline 2 & Richard and May & Couple & $25-30$ & $\begin{array}{l}\text { Graduate - now working - } \\
\text { exports }\end{array}$ & Hangzhou \\
\hline 3 & Leo and Helen & Couple & $20-24$ & Undergraduate students & Ningbo \\
\hline 4 & Kevin and Daniella & Couple & $30-40$ & High School & Dalian \\
\hline 5 & Susan and May & Friends & $25-30$ & $\begin{array}{l}\text { Graduate - now working - } \\
\text { professional }\end{array}$ & Guangzhou \\
\hline 6 & Destiny and Jenny & Couple & $20-24$ & Postgraduate students & Kunming \\
\hline 7 & Swing & Single traveller & $25-30$ & Graduate - now working & Guangzhou \\
\hline 8 & Lilian and Joann & Friends & $20-24$ & Graduate - on graduation trip & Shanghai \\
\hline 9 & Young and Terri & Couple & $25-30$ & $\begin{array}{l}\text { Postgraduates - on post- } \\
\text { graduation trip (doctors) }\end{array}$ & Changsha \\
\hline 10 & Tony and Echo & Couple & $20-24$ & Graduate - on graduation trip & Beijing \\
\hline 11 & Kai and Joy & Couple & $30-40$ & Graduate - (Teachers) & Chengdu \\
\hline 12 & Nemo & Single traveller & $30-40$ & Graduate - IT freelance & Chifeng \\
\hline 13 & Roy and Angela & Couple & $40+$ & Graduate -Engineer / Teacher & Ningbo \\
\hline 14 & Sunny and Liyan & $\begin{array}{l}\text { Mother and } \\
\text { daughter }\end{array}$ & $\begin{array}{l}40+ \\
20-24\end{array}$ & $\begin{array}{l}\text { Company director / } \\
\text { undergraduate student }\end{array}$ & Chengdu \\
\hline 15 & Mai and Donna & Friends & $30-40$ & Graduate - pharmacist & Tianjing \\
\hline 16 & Steed and Iris & Couple & $20-24$ & $\begin{array}{l}\text { Graduate - graduation trip } \\
\text { about to start postgrad }\end{array}$ & Beijing \\
\hline 17 & Lyne and JingJing & Friends & $25-30$ & Graduate - teachers & Shanghai \\
\hline 18 & Anne and Stella & Friends & $20-24$ & $\begin{array}{l}\text { Undergraduate - university } \\
\text { students }\end{array}$ & Shanghai \\
\hline 19 & Paul and Doris & Couple & $30-40$ & $\begin{array}{l}\text { Graduate - management / } \\
\text { teacher }\end{array}$ & Wuhan \\
\hline 20 & Sia and May & Friends & $25-30$ & Graduate - teachers & Shanghai \\
\hline 21 & Rick and Liz & Couple & $25-30$ & Graduate - teachers & Dongguan \\
\hline 22 & Bella and Sanchy & Friends & $25-30$ & Graduate - banking / finance & Shenzhen \\
\hline
\end{tabular}


Interviews were generally carried out in cafés over a drink in a mixture of English and Chinese with the aid of a Chinese translator, with most respondents being keen to practice their English, and only switching to Chinese when needed. For matters of confidentiality, respondent's Chinese names were not taken, but instead respondent's self-given English names are reported in this paper. Many young Chinese have self-chosen English names, often chosen whilst at high school, and in this study, they played a role rather like pseudonyms. Interviews were digitally recorded and later transcribed. Most lasted for around forty minutes discussing a range of topics such as trip organisation, touristic consumption patterns and behaviour and discussion of Chinese and host attitudes towards tourism.

Although the Chinese travellers' interviews held in Pai proved a valuable source of information, due to social desirability bias (Fischer, 1993) and the need to maintain mianzi (face), many were reluctant to freely discuss the motivations behind much of their tourism consumption and production, an issue also reported by Chen and Weiler (2014), whilst others may simply not be aware of their own motivations (Yang et al, 2012). As such, sustained participant observation provided much of the data upon which the following sections are based. Given the touristic nature of many of the Chinese-orientated attractions in Pai, as discussed below, there was little self-conscious altering of tourist behaviour in light of the lead author's presence, as the crowded nature of such attractions allowed the lead author to mingle and observe mostly unnoticed. Whilst many of these performances were unique and unpredictable, there was over time and repeated observation, enough of a degree of repetition and commonality for a detailed empirical understanding of these performances to be developed. Subsequent thematic analysis of Chinese traveller interviews proved insightful in understanding many of the media and online influences that shape existing 'place myths' surrounding Pai, and in hermeneutically reinforcing prior representations and patterns of Chinese tourism consumption. Triangulation of methods and sources (see Denzin, 1978) was then carried out to check consistency and elucidate common themes and findings.

This paper will now turn its attention to the many performances observed in Pai by young independent Chinese travellers. Many of these performances are highly influenced by social culture, with performances based around the creation of online identities of prosperity and status, love and alternative social identities such as Xiao Qing Xing or Chinese hipsterism. 


\section{Performances of prosperity and status}

Perhaps the most numerous and striking of all the performances observed in Pai revolved around the maintenance or strengthening of Chinese middle-class identities and the gaining of social capital. Prayag et al (2015) discussed how some Chinese tourists, like other Asian tourists, feel the need to accumulate social capital and assert a new middle-class identity upon return home, although given the immediacy of social media, it could be argued this now happens whilst on the move. Increasingly, Bourdieu's (1985) notion of accumulating social capital is becoming digital and occurring online (See Phua et al 2017; Yates and Lockley, 2018), and in this aspect, many young Chinese travellers are no different to young travellers from elsewhere. However, culturally specific factors such as the need to build Guanxi based social capital (Lin and Si, 2010) and the need to be seen reaping the benefits of China's modernist development (see Oakes, 1998), mean that the need to accumulate digital social capital is both more important and more noticeable amongst Chinese travellers than from travellers from elsewhere.

Many of these performances revolving around the gaining of social capital in Pai are centred on a few key man-made attractions that form the basis of the main sightseeing day excursion orientated at Chinese tourists. A few enterprising Thai hosts in Pai have started to build manmade attractions along the main valley road that would appeal to Chinese tourists such as Coffee in Love and its fake 'Swiss cottage', Strawberry Farm with its collection of giant- sized concrete painted strawberries, the 'upside-down house' and the 'pink house' (see Figure two). 
Figure 2 - Key man-made Chinese orientated attractions in Pai

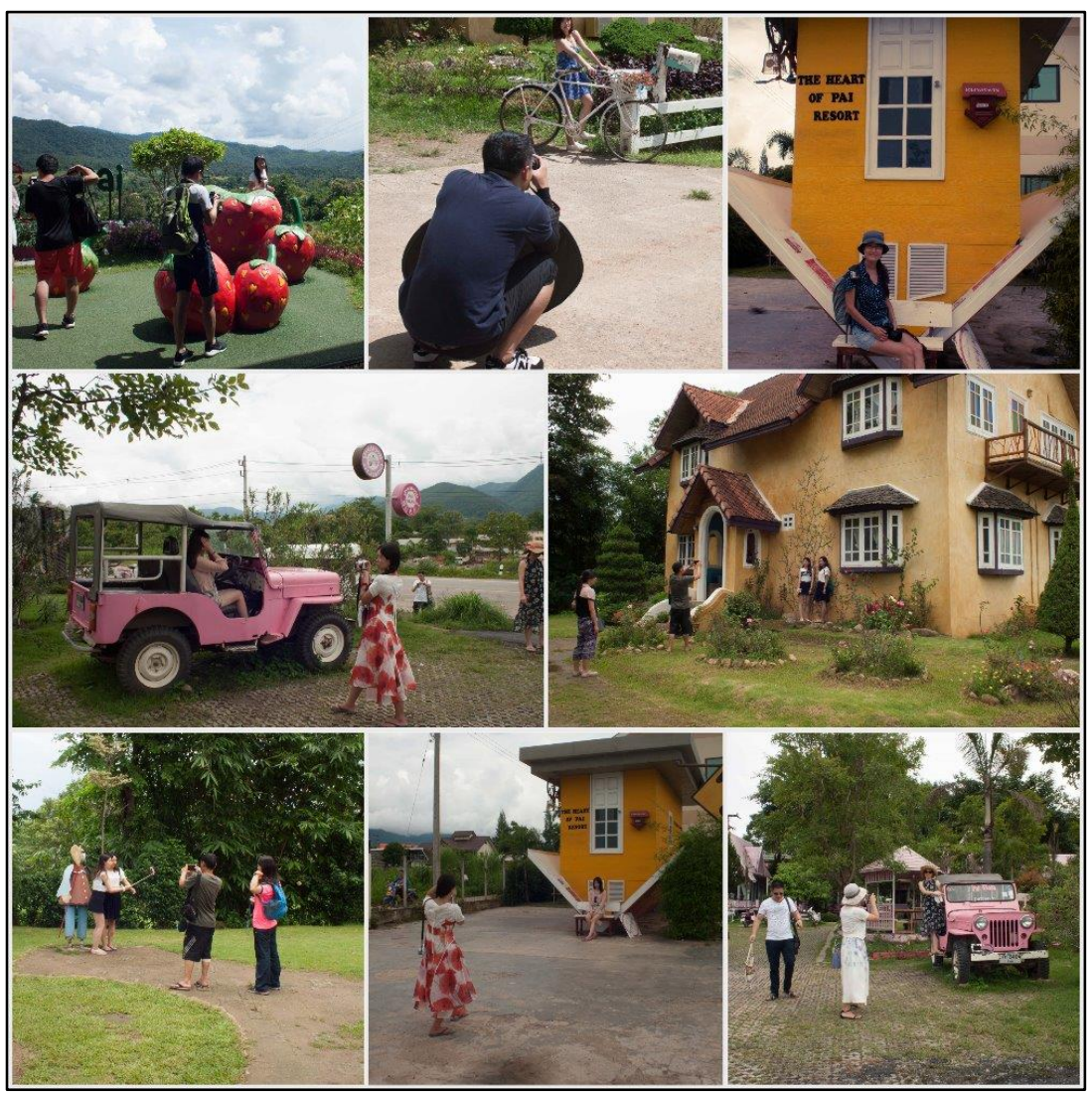

Source - lead author

For most young independent Chinese travellers visiting these man-made attractions in Pai, the overriding purpose was that of tourist photography. Observations from Pai supports comments by Oakes (1998) and Chan (2006) that suggest that few Chinese mass tourists are searching for 'naturalness', authenticity or understanding host communities, and instead prefer for things and places to be touristic or 'Disneyfied' rather than authentic, rejecting places as 'too ordinary' when they lack the trappings of tourism. In a similar vein to Oakes' (1988, p2) observation about rural Guizhou, "Chinese tourists knew they were getting a performance, and expected a performance"; Joy, for instance, praised Pai because;

"Here they spend a lot of...they rack their minds to make a lot of interesting things for tourists"

Among the study's respondents there was also little questioning over whether these manmade attractions should be visited or not, with Susan's comment being typical, "we just went sightseeing according to the tour guide itinerary", and Terri, Anne and Jenny all said, "we just followed the comments of others". 
The digital camera and smart-phone play a crucial role in Pai in capturing and sharing tourist performances and indeed they give reason for the existence of many performances. Larsen (2008) asserts that the digital camera has completely revolutionised the way tourism and tourist photography is carried out. By making photographs 'unlimited', the digital camera has afforded more playful ways of encounter and interacting with tourist attractions in Pai. Scarles' (2009) assertion that photography is increasingly becoming a significant key performance in tourism, central to the whole act of tourism itself, seems well founded. Larsen (2005, p424) is indeed correct to identify that tourist photography is far 'less concerned with spectatorship and "consuming places" than with producing place myths, social roles, and social relationships', and in Pai many of these revolve around increasing social capital and status.

Perhaps most noticeable when observing many of the performances of young Chinese independent travellers in Pai is the extent to which they pose for tourist photographs and attention to detail lavished on many of these performances. Also striking was the manner and level of physicality involved when they interact with these man-made attractions. Static family poses (such as those described by Larsen, 2005 in Denmark) are replaced with outstretched arms, peace signs, pointing and crouching by objects (see Figure three), or even jumping in the air. And while such poses are not solely the reserve of Asian travellers, the extent and degree to which young Chinese travellers pose in playful and striking ways is markedly different from young Western backpackers. Images were collaboratively reviewed and evaluated in the field, and conversations were overheard (and translated) on numerous instances where directions akin to a professional photographer directing a model were overheard.

"Don't put your arm there...next time; turn your head more; your hair needs sorting....." 
Figure 3 - Chinese young independent tourists posing for photos in Pai
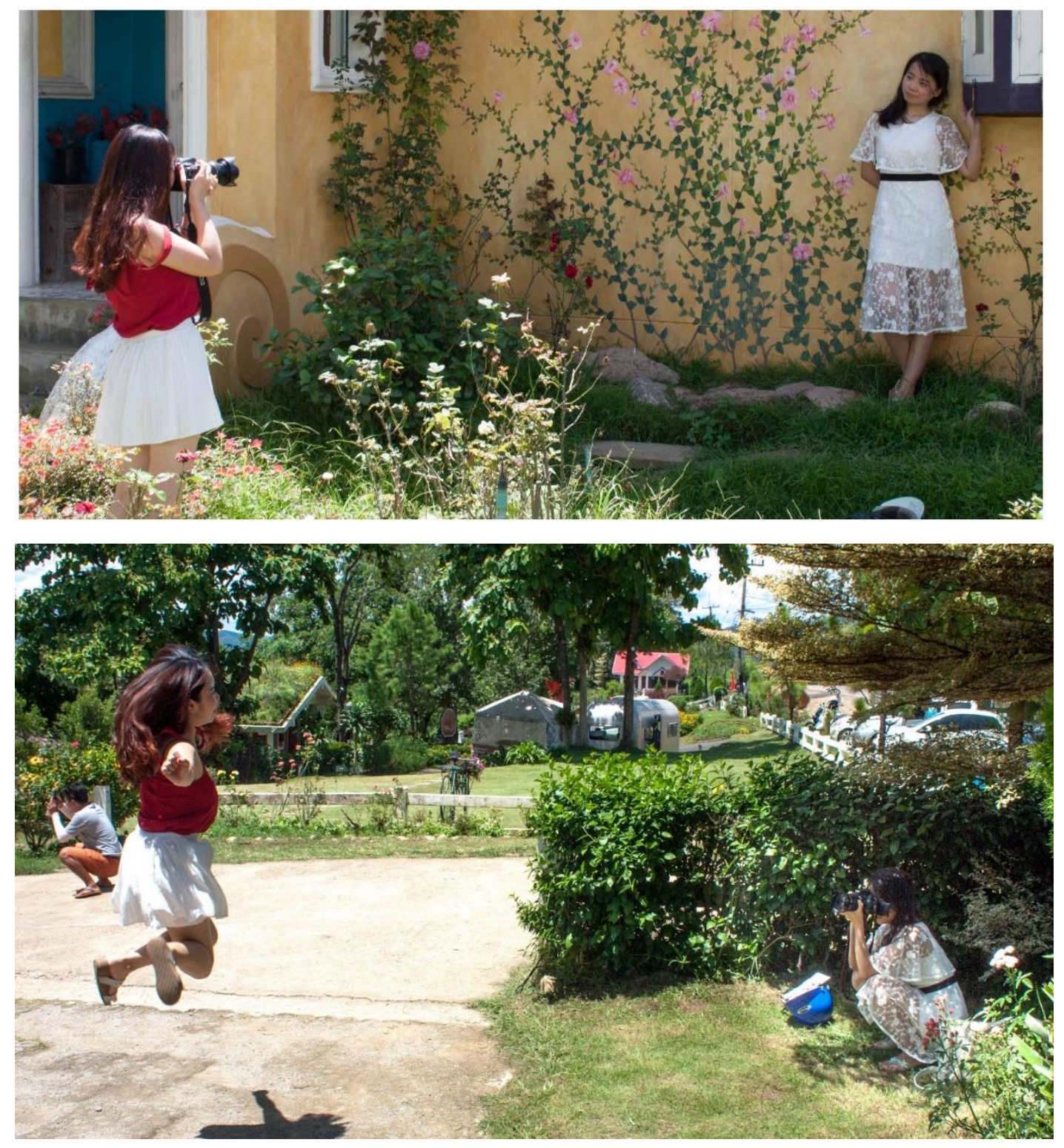

Source - Lead author

Such poses are culturally ingrained in Chinese culture and also Asian culture as a whole, being heavily influenced by the Japanese idea of striking Kawaii (cuteness) poses. With its most famous example being Hello Kitty (Hjorth, 2005), Kawaii culture has its roots in post-Second World War Japan, and its popularity is thought to be in part because its offers a means to overcome the Japanese proclivity for shyness in social interactions. Now it is firmly ingrained in Chinese culture, where selling 'meng' or 'pretending to be cute', influences many of the poses. There is a uniqueness and individuality to many of these poses, and while certain 
typical poses were observed on an almost daily basis, no exact performance or combination of poses will be quite the same.

A combination of physical, material and social affordances enable these performances in Pai, and in particular make these performances both striking and noticeable to their intended audience online in China. Given the sheer number of images posted on Wechat (the Chinese equivalent of Facebook) there is a real risk of performances going un-noticed. What is particularly fascinating is how affordances make Chinese performances in Pai far more noticeable.

Firstly, the man-made attractions where these performances take place, such as Coffee in Love's Swiss cottage, act as stages or backdrops that make such performances more noticeable. On a practical level, the bold colours and simple backgrounds make thumbnail images posted in Wechat social media streams easier to see when users scroll down social media pages. On a deeper level, many of the stages are imbued with symbolic meaning, and in the case of the Swiss cottage, which is 'European' and therefore perceived as modern, it symbolically infers that the subject in the photograph is also, to an extent, modern, middleclass and cosmopolitan. Online representations of Pai mean that many of these attractions provide recognizable places, whether from the movies directly, or from online blogs, that will provide culturally relevant significance and meaning to those in their social groups. For instance, the giant sign 'Coffee in Love' will be instantly recognizable to anyone who has been to Pai, watched the movie, or even considered visiting Pai. Existing 'place myths' and Chinese guidebooks and blogs such as Mafengwo, create a hermeneutic circle (Urry, 1990) that shape and influence Chinese tourism consumption and behavior.

Secondly, materially, the formal and carefully selected clothes or 'costumes' that many young Chinese wear act as 'props' that strengthen performances of prosperity and social capital. One of the most noticeable differences between young Chinese travellers in Pai and their western counterparts is their clothing. Many young Chinese, especially women, dress very formally in comparison to the casual attire of Western backpackers. Zhang and Kim (2013) comment that Chinese apparel preferences are different from those in the West, and Rocha et al (2005) observe that many Chinese have a strong interest in fashion. Chinese female travellers often wore combinations of long flowing floral dresses, sun hats, wrap-around sunshades and coordinated accessories, that can equally be considered to be just as much a 'uniform' 
(Sorensen, 2003; O'Reilly, 2005) as the casual attire worn by western backpackers. Although one reason for such formal attire is due to the common Asian desire to avoid the sun, many young Chinese, predominantly women, dress up smartly on holiday to look good in photographs. Apart from 'looking pretty' (words of the Chinese translator), these 'formal' and 'flamboyant' outfits act as props that enhance and refine performances of social capital. They work in tandem with the man-made tourism spaces in Pai to create strong and noticeable performances that suggest the traveller is middle class, prosperous and cosmopolitan, and that foreign travel is a regular occurrence for them. Indeed many of these outfits will have been carefully selected, with Swing commenting;

"Thailand is an ideal chance to wear a floral dress... which you can't do back at home... But many of the clothes girls wear in Pai will be specially for taking photographs"

The smartphone and the internet provide a vital social role by affording a virtual mooring in the statusphere (Solis, 2009) and a way of distribution and sharing of these performances. For most young Chinese travellers in Pai, social media ensures that they can stay connected and fully integrated with their social networks back home. The level of posting images is often much higher than their western counterparts, so rarely is just one performance posted online, but instead there is a carefully constructed stream of posts. Without the smartphone and online social media platforms, it would be difficult for many of these performances of prosperity and social capital to be shared with a wider audience.

Many young Chinese feel the need to create performances of prosperity and social capital and this is in part culturally influenced. In terms of social capital, Lin and Si (2010) argue that there is a specifically Chinese version of social capital, a guanxi based system, characterized by strong-ties (familial and social ties) that are exceptionally dense. In China, many people rely heavily on personal relations in their social and business lives, and these networks need to be maintained and developed (Ren et al, 2009; Lin \& Si, 2010). Indeed, the connections made at high school and university will typically remain important throughout their lives. Interconnected to the concept of guanxi is the equally important notion of mianzi, which literally translated means 'keeping face'. One's mianzi reflects a person's prestige, a reputation achieved through getting on in life, through success and ostentation (Brunner and Koh, 1999). A person's possession of mianzi requires visible success in matching wellestablished expectations in social hierarchy. It can be treated as his/her social asset and can 
be banked and exchange for favours in the future (Leung \& Yee-Kwong Chan, 2003). Additionally, the Chinese state since 1979 has taken an active role in shaping and promoting modernity in China (Oakes, 1998), and this has also fuelled the need for social capital. The state's narrative of modernity as a rational project of telological socio-cultural transformation, which extols the virtues of modernisation, had created a strong desire for consumption, and to share the signs of this new-found transformation. For Oakes (1998), even in the cities, the stigma of 'backwardness' remains just as much a preoccupation amongst urbanites as it does those from poorer areas, and many feel the need to be 'moving forward'. State narratives that promote consumption and modernisation simply reinforce centuries old notions of guanxi and mianzi.

A key question is the extent and degree of self-awareness behind these performances. Are these young Chinese actively trying to perform, in order, to create social capital, or are they just on holiday, having a good time, and indulging in a culturally ingrained tourist activity? Field interviews in Pai failed to really identify why many Chinese feel so inclined to this unique form of tourism consumption, with respondents downplaying (or self-censoring) the importance of taking photographs, or else justifying their actions.

"My friends keep asking me to post photos of my holiday online, so they can see where I am" - Swing "I just write a blog with my photos so that my family can share the experience" - Mia "I just take a few quick photos of the scenery" - Steed Sniderman and Carmines (1997) and Moufakkir and Reisinger (2013) have all written about the reluctance of people to discuss impulses and traits he/she has, often at the sub-conscious level, but cannot accept. Given the importance of keeping mianzi or 'face' in China, this issue requires further consideration.

\section{Pai in Love}

Not all young Chinese performances in Pai revolve around social capital and prosperity, for many, showing others that they are in love, is equally important. The Chinese rediscovery of the 2009 Thai teen film, 'Pai in Love' has helped to create an image of Pai as a romantic place, a place for young lovers to meet, and this is an image that has been cultivated in Chinese media representations of Pai. Online guide books such as Mafengwo and many online travel 
blogs on Pai have all built upon and cultivated this image of romance and love. Even a quick image search on Baidu (Figure 4) reveals amongst a mix of vintage filtered and Kawaii images, a multitude of romantic and playful images of couples in love.

Figure 4 - Online representations of Pai and 'love'

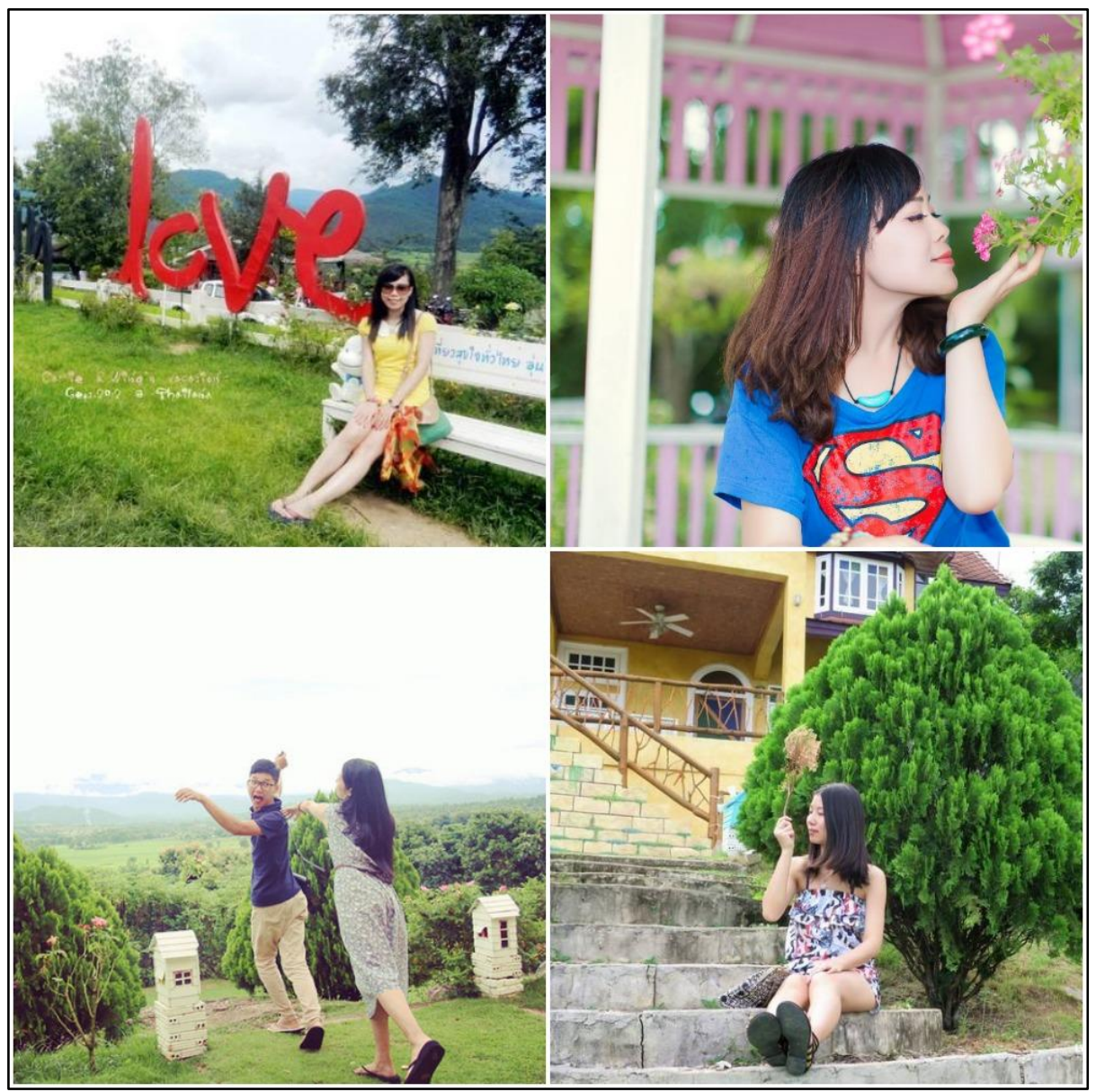

Source - Baidu search 09/11/2018

Such representations of Pai influenced many of the study's respondents, with comments by Bella being typical:

Interviewer: "Why did you think of Pai in the first place?"

Bella: "Because of a movie, 'Pai in love', it's romantic" 
While few would visit Pai solely because of its reputation as a place for 'love', such images and 'place myths' would nevertheless be in the minds of many Chinese who visit Pai, and the movie 'Pai in Love' has certainly played a role in this.

Interviewer: "So why did you come to Pai?"

Donna: "The views.... And the yellow house... because it's very famous"

Interviewer: "Why is it famous?"

Donna: "Because of the film 'Pai in Love', it made me want to come here... yeah.. yeah"

For May, although she admitted she had not actually seen the film, its reputation had in part influenced her decision to visit Pai. These representations of 'love' in media and in discussions of Pai have influenced the gender composition of young Chinese who visit the enclave towards that of couples and pairs of female friends, with Angela (a high school teacher) commenting;

"Some of my friends like Pai very much, especially some young ladies, yes, and they highly recommended it to me"

As a result, these representations are likely to further increase and exaggerate the number of performances related to love. Chan (2007) commented in the case of Chinese visiting Korea, that this mediatized, film induced gaze is most noticeable in female tourists aged eighteen to twenty five.

Many of the respondents interviewed in this study (around 40\%) were young couples who had just graduated from university the previous month, either undergraduate or postgraduate. Young and Terri and Tony and Echo were typical in that their holiday was a special graduation trip and their first holiday together outside of mainland China. As Gao (2016) discusses, graduation trips are carefully planned and important, as they are to celebrate a major milestone in life. The study's Chinese translator also commented: "Now that their studies are finished, it is also a good time for them to develop their relationships and think about marriage". Although the most that Young would somewhat coyly admit was that the aim of his trip with Terri was "to enhance our feelings... (laugh)". Images shared on social media are more than just 'memories of a holiday', they are also performative statement or outward expression to family and friends that they are in love and are aiming to get married, or at least considering marriage. Compared to many western graduates of a similar age, such relationships in mainland China are taken seriously. Confucian values place great importance 
on marriage (Economist, 2016 and Huang \& Gove, 2012), and many young adults and their parents feel under societal pressure to find a suitable partner. Such outward expressions of love are also important in developing an individual's social capital, as one's mianzi is dependent on a person achieving in life (Brunner and Koh, 1999). Mianzi requires visible success in matching well-established expectations in social hierarchy (Leung \& Yee-Kwong Chan, 2003), and one expectation is getting married.

Like all performances observed in Pai, although each couple's performance would be unique and their own 'story' (Ek et al, 2008), they nonetheless can be grouped into three general categories, all revolving around gaining societal approval, captured by digital camera and shared online. Firstly, many general performances would be influenced by notions of Kawaii (cuteness) and would involve holding hands, leaning against each other, fleeting embraces and the running into each other's arms. Such poses were readily observed at many of the Chinese orientated attractions in Pai, and at night along the main walking street. Although few such moments were captured on camera due to the difficulty of capturing them (let alone the ethics of photographing such acts), many would be familiar to those who watch Korean soap operas or even read the many travel blogs on Pai. Many of the Chinese blogs on Pai feature romantic poses and images and advise of romantic spots to visit (usually the places visited in the Chinese orientated excursion tour).

Other performances were shaped by scenes from the movie 'Pai in Love', and as a performance, this is not without precedence. Movie induced tourism has been written about extensively by Beeton (2005), Kim (2010), Connell (2012) and others, and also in an Asian and Chinese context (Chan, 2007; Kim and Wang 2012). Films can provide the objects and subjects for the gaze of many tourists (Hao and Ryan, 2013), but also there can be an 'imagined' aspect (Salazar, 2012). Such tourist 'imaginaries' can lead tourists to reconstruct places in their minds (Chronis, 2012) and even take them into the 'real' space of a film (Couldry, 1998). It is unknown in the case of Pai quite how seriously many young Chinese perform and enact scenes from the movie 'Pai in Love', but research observations show that a number of key scenes and places from the film are popular particularly with couples: the memorial bridge where the heroes of the film sit together, Pai Canyon where many key dialogues occur, Coffee in love café and 'Pai is falling in love' café, where the heroine of the film writes many a lovelorn 
postcard. Even single female tourists travelling with their friend(s) were keen to experience the 'romantic' atmosphere of Pai, with Liyan commenting;

"After seeing the film I wanted to come to Thailand.... I want experience Pai's romantic atmosphere (sic)"

That said, not all not all respondents were enthused by Pai's reputation for 'love', with Kevin on his honeymoon with his wife Daniela commenting somewhat dismissively,

"This place (Pai) is for overly sentimental young kids, those who go "ah, beautiful... ah how beautiful, how fresh"

Given, as Angela commented, how popular 'Pai in Love' is with many (particularly female) young Chinese, the locations of many of these photographs and displays or performances of love shared through Wechat would be readily recognisable by their social group and friends. While few of the respondents, with perhaps the exception of Swing came solely to Pai because of the movie, the film and the destination's image of 'love' encourages performances of love. Choosing to perform and share performances of love at these film locations in Pai will in some cases make their performances more noticeable (at least to female friends of a similar age) and the implicit implication is that love is 'true' like those in the movie. In the case of many of these performances of love, whilst many of these young Chinese were clearly creating their own 'stories' (Ek et al, 2008), nevertheless many of these performances of love seemed to follow existing 'paths' and are influenced by the images and place myths circulating in their culture (Butler and Hall, 1998) resulting in a hermeneutic circle of performances.

\section{Chinese hipsterism}

Pai also has a reputation for being a 'Xiao Qing Xin' destination. Literally translated as 'little fresh' or 'small and fresh', it is an alternative social and fashion movement. The editor of Chinese youth magazine Cityzine describes it as 'Indie Pop' (Huang, 2015), but perhaps Hagerty's (2012) labelling of followers of the movement as 'hipsters' feels more apt, and there are similarities with Western notions of 'hispsterism'. Although perhaps a little condescending, Xiao Qing Xin (XQX) devotees are stereotyped by the wearing of long cotton dresses, converse trainers, chunky black frame glasses and along with a love of nature, vintage analogue photography is very popular. Amongst some, poetry is popular, both Chinese and Japanese (Zhang, 2013). Bergstrom (2012) describes XQX as a hybrid composition of old and 
new, Eastern and Western, mixed with home-grown (mainland Chinese) elements. According to Bergstrom (2012), the result manifests in a simple, thoughtful, clean aesthetic across fashion, design, visual art and music - think shabby chic meets Indie Pop. Quite tribal in membership, its devotees subscribe to a unique set of consumption priorities tied to fashion, creativity and environmentalism.

Photography in XQX is heavily influenced by Japan and by Japanese fashion, with vintage Polaroid and $(35 \mathrm{~mm}$ or $120 \mathrm{~mm})$ film cameras chosen for their aesthetic look and their difference from mainstream culture. Image-wise, the Japanese style of overexposed, whitewashed images focussing on nature or vintage objects is de-rigour. Large aperture prime lenses are preferred, and many follow the Japanese convention of placing subjects in the foreground (Zhihu, 2018) (See Figure 5). For Bergstrom (2012), 'classic' XQX style photos are overexposed shots of girls taking pictures in nature, close ups of simple flowers and cropped angles of blue sky. The lead author, himself a keen photographer, had a particular attuned gaze towards such aspects of analogue photography. Indeed a vintage Rolleiflex camera converted to take Polaroid pictures, carried by the lead author, was used as an icebreaker to build rapport in the interviews. For Nancy and Nathan, they came to Pai because they, "wanted Xiao Qing Xin feelings". Mia was also keen on XQX, but not as serious in that she shot using digital camera filters, but her interest in Pai was in part influenced by XQX (see her photos in figure 6). Other respondents (Jenny, Destiny, Liyan, Sunny, Doris) expressed a desire to experience XQX, with May simply commenting;

"I want to experience Xiao Qing Xin" 
Figure 5 - Xiao Qing Xin photography

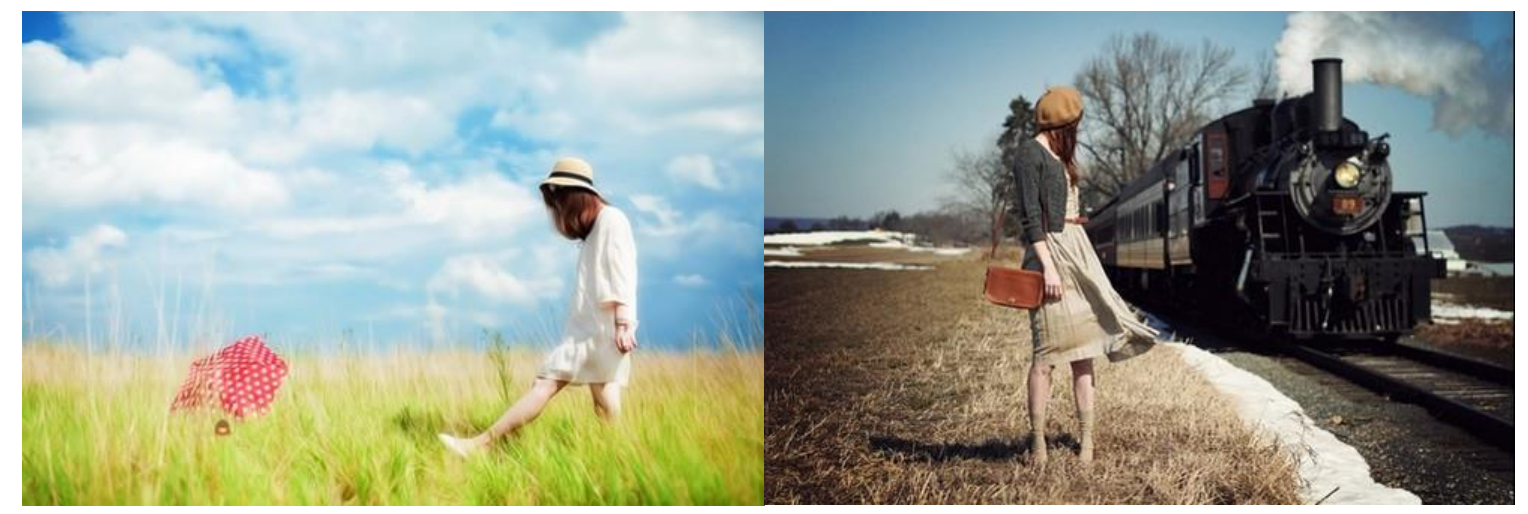

Source - Zhang, 2013

Figure 6 - Xiao Qing Xin photographs taken by Mia in Pai
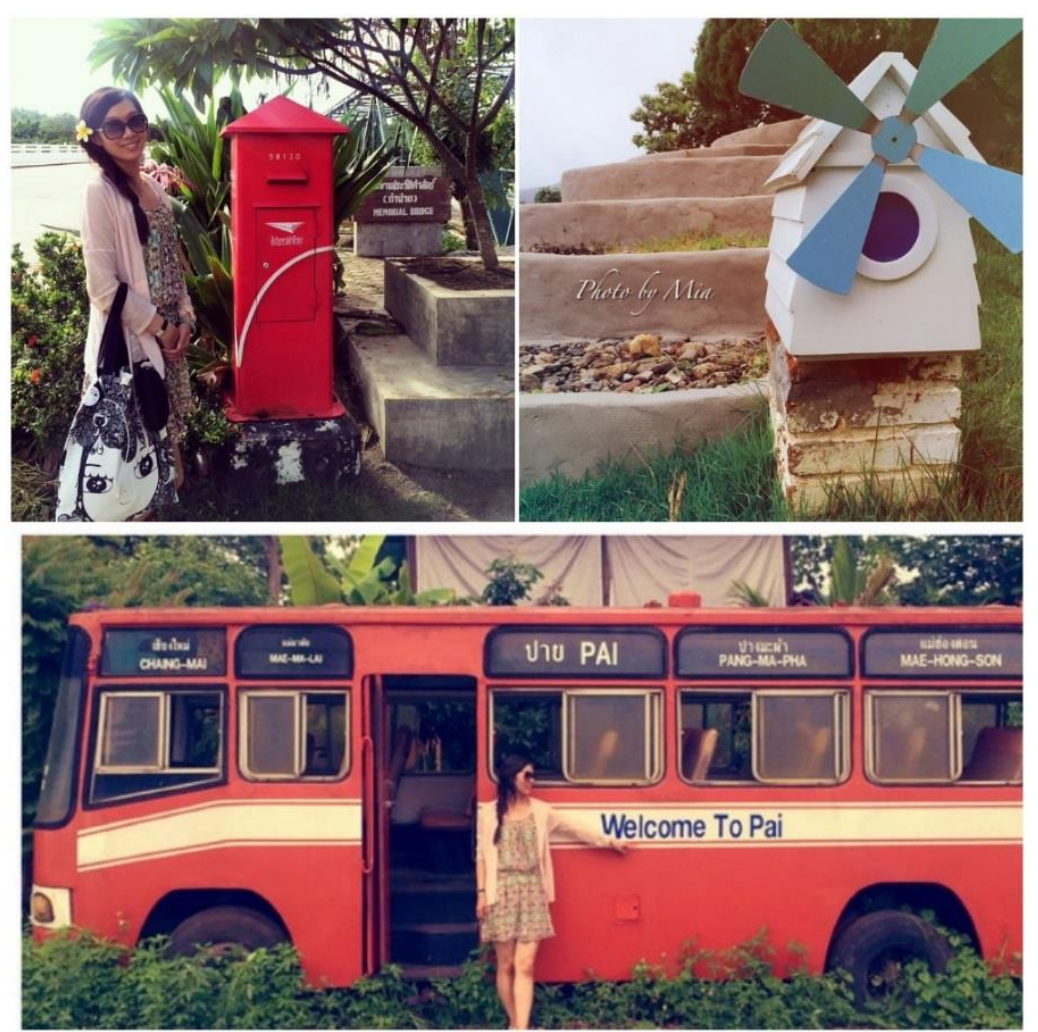

Source - Mia

Online, many guides and blogs extensively mention that Pai is a 'Xiao Qing Xin' destination and a good place to take these kind of photos. As Terri commented:

"For girls it's a good place to take photos.... Because of the blue sky and white clouds... its $X Q X^{\prime \prime}$ 
Whilst Doris, a teacher traveling with her husband Paul commented;

"I read about Chiang Mai and Pai online. I thought I could and should come to Pai because it's quite Xiao Qing Xin"

Whilst this 'Indie Pop' style (Huang, 2015) or 'Asian Hipster' style with concrete walls, vintage, often distressed furniture and thoughtfully selected decorations and an interest in all things analogue (such as old film cameras and vinyl record players) can be found in parts of Chiang Mai and to a lesser extent in parts of Bangkok, it is almost ubiquitous in Pai and in part what makes Pai different from other backpacking destinations such as the Khao San Road in Bangkok. Throughout Pai there are cafés and shops decorated in this style and fashion, and in this aspect the shops in Pai are quite different from in mass tourist destinations elsewhere in Thailand such as Phuket or Pattaya. It is a matter for conjecture quite why there are so many XQX styled cafes and shops in Pai, but the rapid growth and development of Pai means that many buildings in Pai are very new, and therefore enterprising Thais are likely to design any tourism business in a contemporary style, which in addition, given its bare concrete wall minimalism, is likely to reduce building costs.

Many of the young Chinese travellers to Pai are attracted to the XQX nature of Pai and this is reflected in some of the performances observed in Pai. For devotees, a trip to Pai not only provides an opportunity to indulge in their passion of photography, but to strengthen their online social identity amongst peers. For travellers like Nancy and Nathan and others, their performances would be a mixture of filtered mobile phone shots posted on Wechat during the trip and then on their return, their film photos would be carefully developed, scanned then edited before posted online and perhaps on their own blog (like in the case of Mia). The long-winded nature of the process is all seen as part of the dedication needed to be an 'authentic' XQX devotee. For Sinclair (1997) and Sontag (2002) they are 'contemporary flaneurs' armed with cameras that act as an extension of the eye of a flaneur, roaming and riding around Pai looking to capture on film objects, scenes and moments that capture their imagination and reflect a certain outlook and perception on life. Part of the uniqueness of Pai from an XQX perspective, is that if affords a range of photographic possibilities, from posing in a sunlit field next to a babbling river, to posing with a latte next to a record player in a hipster café. Few destinations offer such an extensive range of XQX possibilities, in mainland 
China at least, and this fact has been pickup by the many travel blogs that extol and promote the XQX virtues of Pai.

Performances of $\mathrm{XQX}$ and a desire to create a social identity and be accepted in that group reflect the social isolation that many young Chinese face (Zhang et al, 2017), especially in mega-cities in China. Chen \& Weiler (2014) have written about how many young Chinese are looking for some sense of community in modern urban Chinese life, and this is often found online. Part of the appeal of 'Donkey friends' (Lvyou) or Chinese backpacking is about discovering like-minded individuals who share similar values that at the same time are different from the mainstream. Zhang et al (2017) write about how many young Chinese feel misunderstood by the people who surround them in their daily life, and thus seek 'belonging'. Some young Chinese embrace Chinese donkey friend culture because they feel it is a way of escaping the confines and restrictions of Chinese society, but as Ong and Du Cros (2012) comment, whilst such communities provide the notion of 'freedom', they are actually tightly shaped and maintained by Confucian-endorsed gender rules and roles. There are parallels between Donkey Friends and XQX devotees in that these online social identities, whilst all about freedom are often highly communal and collectivist, exchanging one set of rules for another. Both are characterised by individuals seeking their place in society and by visiting green and traditional places such as Tibet, or Lijiang in Yunnan, a form of 'yearning' for an imaginary way of life they feel has been lost in China.

\section{Conclusions}

By using a performance lens with an emphasis on affordances, this paper identified a range of novel reiterative performances in Pai in northern Thailand by young independent Chinese travellers. Highly influenced by social culture, many of these embodied and virtual performances are based around the maintenance or strengthening of Chinese middle-class identities of prosperity and the gaining of social capital. Other performances are related to love and the creation of alternative social identities such as Xiao Qing Xing or 'little fresh' which reflects an emerging notion of Chinese hipsterism. Many of these performances are made happenable by physical and material affordances, but perhaps the greatest affordances shaping young Chinese traveller performances in Pai are social and are provided by the digital 
camera or smartphone. Without the digital camera and the 'statusphere' there would be no easy way to record or distribute many of the performances observed, and without such technology it would be difficult to produce many of these performances. These 'non-human actors' (Beard et al, 2016) play an important role in combining with human actors to produce hybrid performances and facilitate the production and consumption of tourism.

It is also important to acknowledge that all tourists perform, and that these performances are also culturally specific and largely ingrained. For instance Western backpackers also perform and seek social capital amongst their social peers, using Facebook instead of Wechat, just in very different ways, with social capital gained through the creation of narratives that strengthen their identities as 'real' travellers and their ability to 'rough it' in the most 'authentic' destination (O'Reilly, 2006). Tourism performances are not the preserve of any one group or nationality, but this study highlights how different performances can be in a particular cultural context. A key contribution of this paper is that it has provided new insights into the nature and 'Chinese characteristics' (Lim, 2009; Chen et al, 2013) of young independent Chinese travellers in northern Thailand. What is perhaps best highlighted here through the use of a performance lens is quite how much tourism consumption in Pai revolves around the need to create and produce performances for an online audience back in mainland China. Also of importance is the degree to which this study has revealed that Chinese touristic production and consumption is shaped by film, social media and online guidebooks such as Mafengwo. More broadly, it emerges from this study that there are young Chinese travellers who are quite different from Chinese tour groups with their alleged 'messy behaviour' (Chan, 2006) and Chinese Donkey friends (Lvyou) with their fascination with Tibet (Lim, 2009, Luo et al, 2015). These young Chinese independent travellers are yet another new segment of traveller in a rapidly evolving and heterogeneous Chinese outbound tourism market.

Notwithstanding the preceding discussion, some limitations to the study should be noted. This study is not representative, given its qualitative approach, focussed on one tourism destination in northern Thailand. Given the lack of previous research on the performances of young independent Chinese travellers, or any segment of Chinese tourist for that matter, multi-sited follow-up research into the performances of Chinese travellers elsewhere is required. For instance, is there something unique about Pai with its reputation as a place of 'love' and as a Xiao Qing Xin destination that makes it special in terms of the amount, 
frequency and type of performances observed? Can any of these performances be observed elsewhere? Furthermore, questions remain unanswered about the extent and degree of selfawareness behind such performances. Many young Chinese may be actively trying to build social status in these performances, but this is something they were largely unwilling to discuss. There are therefore still unanswered questions about the extent and degree of prepresentational and pre-choreographed aspects of performances, and how these potentially sub-conscious motivators can be methodologically uncovered.

As research on Chinese tourists evolves and develops, there is a need to consider new tourism research perspectives. Chinese tourism research had yet to embrace performance perspectives or drawn on the importance of affordances and materialities in co-constructing social life. Based on the case of young independent Chinese travellers in Pai in Thailand, this paper has demonstrated that much of tourism consumption revolves around the production of performances, and that a performance lens can contribute new understandings of Chinese tourism consumption.

\section{$\underline{\text { References }}$}

Armstrong, P \& Wang, Y. (2018). The billion dollar race to become the Netflix of China. Forbes, $7^{\text {th }}$ March 2018. URL accessed 05/11/2018 https://www.forbes.com/sites/ywang/2018/03/07/the-billion-dollar-race-tobecome-the-netflix-of-china/\#6101393a3495

Austin, J. L. (1955). How to do things with words. Oxford University Pres

Baerenholdt, O. H., \& Haldrup, M. M., Larsen, J. and Urry, J.(2004) Performing Tourist Places.

Barthes, R. (2000). The photographic message. Theorizing communication: readings across traditions, 191-199.

Beard, L., Scarles, C., \& Tribe, J. (2016). Mess and method: Using ANT in tourism research. Annals of Tourism Research, 60, 97-110.

Beeton S (2005) Film-Induced Tourism. Clevedon: Channel View Publications

Bergstrom, M. (2012). All eyes East: Lessons from the front lines of marketing to China's youth. Macmillan.

Bourdieu, P., \& Whiteside, S. (1996). Photography: A middle-brow art. Stanford University Press.

Brunner, J. A., \& Koh, A. C. (1989). Negotiations in the People's Republic of China: An empirical survey of American and Chinese negotiators' perceptions and practices. Journal of Global Marketing, 2(1), 33-56.

Butler, J. (1993). Critically queer. GLQ: A journal of Lesbian and Gay Studies, 1(1), 17-32.

Butler,R.W. \& Hall, C.M. (1998). Image and reimaging of rural areas. In R.W. Butler, C.M. Hall \& J. Jenkins (Eds.), Tourism and recreation in rural areas (pp. 115-122). Chichester and Wiley 
Cederholm, E. A. (2004). The use of photo-elicitation in tourism research-framing the backpacker experience. Scandinavian Journal of Hospitality and Tourism, 4(3), 225-241.

Chan, B. (2007). Film-induced tourism in Asia: A case study of Korean television drama and female viewers' motivation to visit Korea. Tourism Culture \& Communication, 7(3), 207-224.

Chan, Y. W. (2006). Coming of age of the Chinese tourists: The emergence of non-Western tourism and hostguest interactions in Vietnam's border tourism. Tourist studies, 6(3), 187-213.

Chemero, A. (2003). An outline of a theory of affordances. Ecological psychology, 15(2), 181-195.

Chen, G., Bao, J., \& Huang, S. S. (2014). Segmenting Chinese backpackers by travel motivations.

Chen, H., \& Weiler, B. (2014). Chinese Donkey Friends in Tibet-Evidence from the Cyberspace Community. Journal of China Tourism Research, 10(4), 475-492.

Chronis, A. (2012). Between place and story: Gettysburg as tourism imaginary. Annals of Tourism Research, 39(4), 1797-1816

Cohen, E. (2006). Pai-a backpacker enclave in transition. Tourism Recreation Research, 31(3), 11-27.

Cohen, S., \& Cohen, E. (2017). New directions in the sociology of tourism. Current Issues in Tourism, doi: $10.1080 / 13683500.2017 .1347151$

Connell, J. (2012). Film tourism: Evolution, progress and prospects. Tourism Management, 33(5), 1007-1029.

Couldry, N. (1998). The view from inside the 'simulacrum': Visitors' tales from the set of coronation street. Leisure Studies, 17, 94-107.

Crouch, D. (2000). Places around us: Embodied lay geographies in leisure and tourism. Leisure studies, 19(2), 63-76.

Crouch, D. (2003). Spacing, performing, and becoming: tangles in the mundane. Environment and Planning A, 35(11), 1945-1960

Crouch, D. (2004). Tourist practices and performances. A companion to tourism, 85-96.

Denzin, N. K. (1978). The research act: A theoretical orientation to sociological methods.

Dogtiev, A (2018). WeChat Revenue and Usage Statistics. Business of Apps. URL accessed 5/11/2018 http://www.businessofapps.com/data/wechat-statistics/

Doorne, S., \& Ateljevic, I. (2005). Tourism performance as metaphor: Enacting backpacker travel in the Fiji Islands. Discourse, communication and tourism, 173-198.

Economist (2016, $7^{\text {th }}$ July). Family, identity and morality: a nation of individuals. The Economist Special report, $7^{\text {th }}$ July 2016. Web URL accessed 28/5/2018 https://www.economist.com/special-report/2016/07/07/a-nationof-individuals

Edensor, T. (1998). The Tourist at the Taj. London. Rutledge. pp, 12-22.

Edensor, T. (2000). Staging tourism: Tourists as performers. Annals of tourism Research, 27(2), 322-344.

Edensor, T. (2001). Performing tourism, staging tourism: (Re) producing tourist space and practice. Tourist studies, 1(1), 59-81.

Edensor, T. (2006). Sensing tourist spaces. Travels in paradox: Remapping tourism, 23-45.

Ek, R., Larsen, J., Hornskov, S. B., \& Mansfeldt, O. K. (2008). A dynamic framework of tourist experiences: Space-time and performances in the experience economy. Scandinavian Journal of Hospitality and Tourism, 8(2), 122-140. 
Fisher, R. J. (1993). Social desirability bias and the validity of indirect questioning. Journal of consumer research, 20(2), 303-315.

Franklin, A., \& Crang, M. (2001). The trouble with tourism and travel theory?.

Gao, X. (2016). To stay or not to stay in Hong Kong: An examination of Mainland Chinese undergraduates' after-graduation plans. In Internationalization of Higher Education (pp. 185-203). Springer, Singapore

Germann Molz, J., \& Paris, C. M. (2015). The social affordances of flashpacking: Exploring the mobility nexus of travel and communication. Mobilities, 10(2), 173-192.

Gibson, J. J. (1979). The theory of affordances. The people, place, and space reader, 56-60.

Goffman, E. (1959). The Presentation of Self in. Butler, Bodies that Matter.

Gregson, N., \& Rose, G. (2000). Taking Butler elsewhere: performativities, spatialities and subjectivities. Environment and Planning D: Society and space, 18(4), 433-452.

Hagerty, L (2012). On the banks of the mainstream. GU Office of Global education: Student Blog. Web URL accessed 24/5/2018 https://blogs.commons.georgetown.edu/studyabroad/2012/11/28/on-the-banks-of-themainstream/

Haldrup, M., \& Larsen, J. (2009). Tourism, performance and the everyday: Consuming the orient. Routledge.

Hao, X., \& Ryan, C. (2013). Interpretation, film language and tourist destinations: a case study of Hibiscus Town, China. Annals of Tourism Research, 42, 334-358.

Harrison, B. (2004). Snap happy: Toward a sociology of "everyday" photography. In Seeing is believing? Approaches to visual research (pp. 23-39)

Hirsch, D (2016). Coffee in Love in Thailand. 2foodtrippers blog. Web URL accessed 25/05/2018 https://www.2foodtrippers.com/coffee-in-love-in-thailand/

Hjorth, L. (2005). Odours of mobility: Mobile phones and Japanese cute culture in the Asia-Pacific. Journal of Intercultural Studies, 26(1-2), 39-55

Huang, G. H. C., \& Gove, M. (2012). Confucianism and Chinese families: Values and practices in education. International Journal of Humanities \& Social Science, 2, 10-16

Huang, X (2015). Aesthetic preference shift of the Chinese young generation. Yang Design. Web URL accessed 28/05/2018 https://www.linkedin.com/pulse/aesthetic-preference-shift-chinese-young-generation-xiaojinghuang

Jensen, M.T., Scarles, C. \& Cohen, S.A. (2015). A multisensory phenomenology of interrail mobilities. Annals of Tourism Research, 53, 61-76.

Jóhannesson, G. T. (2005). Tourism translations: Actor-network theory and tourism research. Tourist Studies, 5(2), 133-150.

Kampungboycitygal (2015). 10 Things to do in Pai, Thailand. KampungboyCitygal: A Malaysian food and travel blog. Web Url accessed 25/5/2018 kampungboycitygal.com/2015/05/10-things-to-do-in-pai-thailand/

Kim S (2010) Extraordinary experience: Re-enacting and photographing at screen-tourism locations. Tourism and Hospitality Planning and Development 7(1): 59-75

Kim, S., \& Wang, H. (2012). From television to the film set: Korean drama Daejanggeum drives Chinese, Taiwanese, Japanese and Thai audiences to screen-tourism. International Communication Gazette, 74(5), 423442. 
Larsen, J. (2005). Families seen sightseeing: Performativity of tourist photography. Space and culture, 8(4), 416-434.

Larsen, J. (2008). Practices and flows of digital photography: An ethnographic framework. Mobilities, 3(1), 141160.

Larsen, J., \& Urry, J. (2011). Gazing and Performing. Environment and Planning D: Society and Space, 29(6), 1110-1125.

Larsen, J., \& Sandbye, M. (2014). The (im) mobile life of digital photographs: the case of tourist photography. Digital snaps: The new face of photography, 25-46

Leung, T. K., \& Yee-kwong Chan, R. (2003). Face, favour and positioning-a Chinese power game. European Journal of Marketing, 37(11/12), 1575-1598.

Li, M., Sharpley, R., \& Gammon, S. (2017). Towards an understanding of Chinese tourist photography: Evidence from the UK. Current Issues in Tourism, 1-20.

Lim, F. K. G. (2009). Donkey friends' in China: the Internet, civil society and the emergence of the Chinese backpaking community. In Asia on tour: Exploring the rise of Asian tourism(pp. 291-301).

Lin, J., \& Si, S. X. (2010). Can guanxi be a problem? Contexts, ties, and some unfavorable consequences of social capital in China. Asia Pacific Journal of Management, 27(3), 561-581.

Lo, I. S., McKercher, B., Lo, A., Cheung, C., \& Law, R. (2011). Tourism and online photography. Tourism Management, 32(4), 725-731.

Luo, X., Brown, G., \& Huang, S. S. (2015). Host perceptions of backpackers: Examining the influence of intergroup contact. Tourism Management, 50, 292-305.

Meeker, M. (2013). Internet trends report. Kleiner Perkins Caufield \& Byers: Snyder, TX, USA.

Moufakkir, O., \& Reisinger, Y. (2013). The host gaze in global tourism. The host gaze in global tourism.

O’Reilly, C. C. (2006). From drifter to gap year tourist: Mainstreaming backpacker travel. Annals of tourism research, 33(4), 998-1017.

Oakes, T. (1998). Tourism and modernity in China.

Omnicore (2018). Instagram by the numbers: stats, demographics and fun facts. Omnicore. URL accessed 5/11/2018 https://www.omnicoreagency.com/instagram-statistics/

Ong, C. E., \& du Cros, H. (2012). The post-Mao gazes: Chinese backpackers in Macau. Annals of Tourism Research, 39(2), 735-754.

Papish, J. (2017). Foreign Films in China: how does it work? China Film Insider. URL accessed 05/11/2018 http://chinafilminsider.com/foreign-films-in-china-how-does-it-work/

Phua, J., Jin, S. V., \& Kim, J. J. (2017). Uses and gratifications of social networking sites for bridging and bonding social capital: A comparison of Facebook, Twitter, Instagram, and Snapchat. Computers in Human Behavior, 72, 115-122.

Prayag, G., Cohen, S. A., \& Yan, H. (2014). Potential Chinese travellers to Western Europe: Segmenting motivations and service expectations. Current Issues in Tourism, 18(8), 725-743.

Prayag, G., Disegna, M., Cohen, S. A., \& Yan, H. (2015). Segmenting markets by bagged clustering: Young Chinese travellers to Western Europe. Journal of Travel Research, 54(2), 234-250.

Rantala, O. (2010). Tourist practices in the forest. Annals of Tourism Research, 37(1), 249-264. 
Ren, Bing, Kevin Y. Au, and Thomas A. Birtch. "China's business network structure during institutional transitions." Asia Pacific Journal of Management 26, no. 2 (2009): 219-240.

Rocha, M. A. V., Hammond, L., \& Hawkins, D. (2005). Age, gender and national factors in fashion consumption. Journal of Fashion Marketing and Management: An International Journal, 9(4), 380-390.

Salazar, N. (2012). Tourism imaginaries: A conceptual approach. Annals of Tourism Research, 39(2), 863-882.

Scarles, C. (2009). Becoming tourist: Renegotiating the visual in the tourist experience. Environment and Planning D: Society and Space, 27(3), 465-488

Scott, (2018). Wechat is a way of life for 900 million daily users. Intheblack.com. URL accessed 05/11/2018 https://www.intheblack.com/articles/2018/05/01/wechat-super-app

Sung, Y., Lee, J. A., Kim, E., \& Choi, S. M. (2016). Why we post selfies: Understanding motivations for posting pictures of oneself. Personality and Individual Differences, 97, 260-265.

De Seta, G., \& Proksell, M. (2015). The aesthetics of zipai: From WeChat selfies to self-representation in contemporary Chinese art and photography. Networking Knowledge: Journal of the MeCCSA Postgraduate Network, 8(6).

Sinclair, I. (1997). Lights Out for the Territory: Nine Excursions in the Secret History of London.

Sniderman, P. M., \& Carmines, E. G. (1997). Reaching beyond race. Harvard University Press.

Solis, B. (2009). Are blogs losing their authority to the statusphere. TechCrunch. Retrieved March, 22, 2010.

Sontag, S. (2002). On Photography/Susan Sontag.

Sørensen, A. (2003). Backpacker ethnography. Annals of tourism research, 30(4), 847-867.

Thaitrakulpanich, A (2016). Thai soap exports making waves in mainland China. Prachatatai English. Web URL accessed 28/5/2018 https://prachatai.com/english/node/6076

Thrift, N. (1997). The still point. Geographies of resistance, 124-151.

Thrift, N. (2000). Performing cultures in the new economy. Annals of the association of American Geographers, 90(4), 674-692.

Urry, J. (1990). Tourist Gaze: Leisure and Travel in Contemporary Societies (Theory, culture \& society). Sage publications

Veijola, S., \& Jokinen, E. (1994). The body in tourism. Theory, Culture \& Society, 11(3), 125-151.

Veijola, S., \& Valtonen, A. (2007). The body in tourism industry. Tourism and gender: Embodiment, sensuality and experience, 13-31.

Velten, H. R. (2012). Performativity and Performance. Travelling Concepts for the Study of Culture, 2, 249.

Wearing, B., \& Wearing, S. (1996). Refocussing the tourist experience: The flaneur and the choraster. Leisure studies, 15(4), 229-243.

Whitty, M. T., \& McLaughlin, D. (2007). Online recreation: The relationship between loneliness, Internet selfefficacy and the use of the Internet for entertainment purposes. Computers in Human Behavior, 23(3), 1435 1446.

Yang, Q., \& Li, Z. (2014). A picture is worth a thousand words: Chinese college students' self-presentation on social networking sites. Journal of Communications Media Studies, 6(1), 70-94.

Yang, J., Ryan, C., \& Zhang, L. (2012). The use of questionnaires in Chinese tourism research. Annals of Tourism Research, 39(3), 1690-1693. 
Yates, S., \& Lockley, E. (2018). Social media and social class. American Behavioral Scientist, 0002764218773821.

Yeh, J.H (2009). The embodiment of sociability through the tourist camera. In M. Robinson, D. Picard (Eds), The framed world: Tourism, tourists and photography, Ashgate, Aldershot, UK (2009), pp. 199-216

Zhang, A (2013). Rise of the Xiaoqinxin. The World of Chinese. Web URL accessed 24/5/208 www.theworldofchinese.com/2013/05/the-rise-of-the-xiaoqingxin/

Zhang, B., \& Kim, J. H. (2013). Luxury fashion consumption in China: Factors affecting attitude and purchase intent. Journal of Retailing and Consumer Services, 20(1), 68-79.

Zhang, J., Morrison, A. M., Tucker, H., \& Wu, B. (2017). Am I a backpacker? Factors indicating the social identity of Chinese backpackers. Journal of Travel Research, 0047287517702744.

Zhihu, Z (2018). About Japanese small fresh shoot! Web URL accessed 24/5/2018 https://zhuanlan.zhihu.com/p/23741856

Zhu, J (2013. May 3). Chinese tourists flock to Thailand thanks to hit comedy film. Financial Times. Web URL accessed 28/5/2018 https://www.ft.com/content/73cf449a-2529-3fc7-976d-610f2e63bfe4 